\title{
Analysis and targeting of waste paper/polyester composites after weathering
}

\author{
Jussara Smidt Porto a, Clarissa Coussirat Angrizani ${ }^{a}$ Eliana Paula Calegari ${ }^{b}$, Sandro Campos Amico ${ }^{a}$, Lauren da Cunha Duarte ${ }^{a}$ \\ Unniversidade Federal do Rio Grande do Sul \\ IInstituto Federal de Rondônia \\ e-mails: jussara.porto@ufrgs.br; cangrizani@gmail.com; elianapaulac@gmail.com; amico@ufrgs.br; lauren.duarte@ufrgs.br
}

\begin{abstract}
This paper focuses on the investigation of degradation effects from the environment on waste paper/polyester composites. The materials were analyzed according to visual aspects, mass gain and mechanical properties. The composites subjected to aging were influenced by moisture absorption from the particles, with a deleterious effect also on particle/matrix interface, decreasing tensile and flexural strength of the composite. This same phenomenon lead to a positive effect on impact strength and reduction in hardness of the composites, since moisture absorption was limited and the material became slightly tougher. Moisture absorption also caused an increase in elastic modulus of the matrix. Based on all results, the developed material was found not suitable for external use.
\end{abstract}

Keywords: waste paper, composite, aging, mechanical properties.

\section{Introduction}

The growth of a country's economy and per capita income demand for natural resources and manufactured products, resulting in large amounts of waste generated and damage to the environment (LIU et al., 2015). Facing this scenario, strategies for reuse, remanufacturing and recycling have been suggested (SCALICE; BECKER; SILVEIRA, 2009). According to Faruk et al. (2012), due to environmental problems and new regulatory requirements, there is an increase in the development of non-conventional materials, e.g. new polymeric composite materials.

In the process of material development, knowledge of its characteristics and behavior are fundamental to allow the development of products (ASHBY; JOHNSON, 2014). In this context, the paper industry brings challenges and opportunities. In Brazil, for instance, there is a large availability of waste paper and only $37 \%$ of it is reused to produce new paper (PORTAL RESÍDUOS SÓLIDOS, 2018). The use of waste paper in composites has been studied by researchers such as Prambauera et al. (2015), who reported that these composites can have different applications due to the sustainability, availability and even economic benefits of the paper in terms of recycling.

Polymer composite materials when exposed to the natural environment, water or high temperatures undergo changes in their physical, mechanical and chemical properties. Water absorbed under these conditions tends to be located in the matrix or in the fiber/matrix interface. Composites constituted by lignocellulosic fibers have greater risk of change in properties when submitted to external applications compared to composites reinforced by synthetic fibers (AZWA et al., 2013) due to the hydrophilic nature of the former, which facilitates water absorption, dimensional changes among others (MAZZANTI; MOLLICA, 2017). There is a downward trend in the properties most dependent on the reinforcement because the water/moisture absorption creates inefficient matrix/reinforcement load transfer regions. Moreover, the matrix and the reinforcement have a swelling difference (AKIL et al., 2014), and sorbed water can act as plasticizer, simultaneously influencing fibers, matrix and interface.

Degradation caused by climatic agents can be investigated through environmental exposure (natural aging) or accelerated aging (CHAN et al., 2019). Natural aging approximates the actual conditions of material usage, where degradation caused by climatic agents can be analyzed, but it requires long exposure times. According to Belec et al. (2015), the effects of UV radiation or hygrothermal stresses have been separately studied, but the study of these combined effects found in natural aging are not yet clear. In this context, this paper focuses on the investigation of natural degradation effects on waste paper/polyester composites at very high paper content.

\section{Methodology}

\subsection{Materials}

Chopped waste paper from UFRGS printing processes, in Porto Alegre/RS, Brazil, was used. The waste paper was obtained from different finishing equipment, the 
Mini Max Drilling Machine and the Heidelberg Eurobind Colander. The original paper is the offset from International Paper, grammage $75 \mathrm{~g} / \mathrm{m}^{2}$ and moisture content of $6 \%$, in the dimensions of $\approx 2 \mathrm{~mm}$ for the smaller paper (PME) and $\approx 5 \mathrm{~mm}$ for the larger paper (PMA).

Reichhold's orthophthalic unsaturated polyester (PO) resin and Butanox M-50 initiator $(1.3 \% \mathrm{v} / \mathrm{v})$ were also used. Unsaturated polyester was chosen as matrix due to its advantages related to low cost and good processability, being widely used in composites reinforced with vegetable fibers (PENCZEK; CZUB; PIELICHOWSKI, 2005).

\subsection{Preparation of composites}

The first stage consisted in the selection of the waste (in relation to their size and type of paper) and drying of the chopped paper in an oven with air circulation for $2 \mathrm{~h}$ at $60{ }^{\circ} \mathrm{C}$. The paper waste was then weighed, manually mixed with the polyester/initiator mixture, and cast into a metal mold (cavity dimensions: $17 \mathrm{~cm} \times 27 \mathrm{~cm} \times 0.35 \mathrm{~cm}$ ). Afterwards, the material was hot compression molded in a Marconi hydraulic press MA 098/A model under $3 \mathrm{bar}$, for $75 \mathrm{~min}$ at $80^{\circ} \mathrm{C}$, which resulted in resin curing. The composites were later post-cured in air circulation oven at $60{ }^{\circ} \mathrm{C}$ for $4 \mathrm{~h}$.

Polyester/smaller paper (PO/PME) and polyester/larger paper (PO/PMA) composites with $80 \% \mathrm{v} / \mathrm{v}$ of paper were produced with the intention of maximizing the usage of residue. Specimens were obtained from the plates using a laser cutting equipment Automatisa Mira 3007 model to reduce premature damage to the specimens.

\subsection{Characterization of composites}

Qualitative and quantitative analyzes were performed before/after natural aging. Regarding the visual aspect, brightness, color and the presence of imperfections were monitored with a Nikon model D3300 digital camera. Mass changes of the composites were monitored by weighing the specimens before and after aging.

Density of the samples was evaluated based on Archimedes' principle. The following values were found: $1.19 \pm 0.02 \mathrm{~g} / \mathrm{cm}^{3}, 1.32 \pm 0.02 \mathrm{~g} / \mathrm{cm}^{3}$ and $1.22 \pm 0.02 \mathrm{~g} / \mathrm{cm}^{3}$ for $\mathrm{PO}, \mathrm{PO} / \mathrm{PME}$ and $\mathrm{PO} / \mathrm{PMA}$, respectively.

Tensile test was performed according to ASTM D3039 in an Instron 3382 universal testing machine ( $100 \mathrm{kN}$ load cell) at a speed of $2 \mathrm{~mm} / \mathrm{min}$. Elasticity modulus was obtained with a video extensometer. Flexural test was performed according to ASTM D790, in an Emic 23-5D equipment (5 $\mathrm{kN}$ load cell). Shore D hardness measurements were taken using a Bareiss equipment following ASTM D2240. Twenty readings were taken for each sample, and the mean value was obtained. Izod impact testing was performed on notched samples according to ASTM D256 using an Impactor II model Ceast equipment with a $2.75 \mathrm{~J}$ hammer. The notches were produced in a Notchvis model Ceast equipment.

In each type of material, at least six specimens were analyzed without natural aging and other six after natural aging. The results of the mechanical tests were analyzed statistically with the single-factor Anova to compare different groups and verify similarity between pairs (ANGRIZANI et al., 2014). The Anova is represented by letters in the graphs and tables of results, and equal letters denote that there is no significant difference between families of specimens.

\subsection{Natural aging}

The specimens to be aged were placed in an iron structure at $30^{\circ}$ inclination and under a nylon mesh (see Figure 1a) (ASTM D1435) for a period of 180 days (6 months), from January 23, 2017 to July 23, 2017, in Porto Alegre city. This period comprised summer, autumn and winter seasons, and the geographical location was: latitude $\left(30^{\circ} 05^{\prime}\right.$ South), longitude $\left(51^{\circ} 11^{\prime}\right.$ West) and altitude $(174 \mathrm{~m})$, which allows normal incidence of solar radiation over the entire surface of the exposed samples.

Data of the climatic conditions were obtained from the Meteorological National Institute, for a meteorological station also located in Porto Alegre city. Figure $1 \mathrm{~b}$ shows a summary of the climatic conditions during the 6-month period of exposure of the specimens, including values of maximum ultraviolet radiation (UV), precipitation, and maximum and minimum temperature recorded. In relation to ultraviolet radiation, higher values are concentrated at the beginning of the test (January-February), corresponding to the summer period. The highest UV peak was between 160 and 180 days, which corresponds to June, reaching around $6400 \mathrm{~kJ} / \mathrm{m}^{2}$. Maximum temperatures were recorded at the beginning of the period, January and February, and minimum temperatures were recorded in the winter months, end June and July. Precipitation was verified on different periods, with greater intensity between days 40 and 50, 80 and 140, reaching $70 \mathrm{~mm}$.

\section{Results and discussion}

\subsection{Preliminary analysis}

Random arrangement of the waste paper in the matrix was obtained and the material with smaller paper (PME) had a smoother surface, while the one with larger paper (PMA) had a more irregular surface. Due to the polyester translucency, paper chips can be observed in both the smaller and the larger paper composites (Figure 2a, c) resulting in a heterogeneous texture. Both composites have a suitable quality for the development of products focusing on the sustainable aspect. 

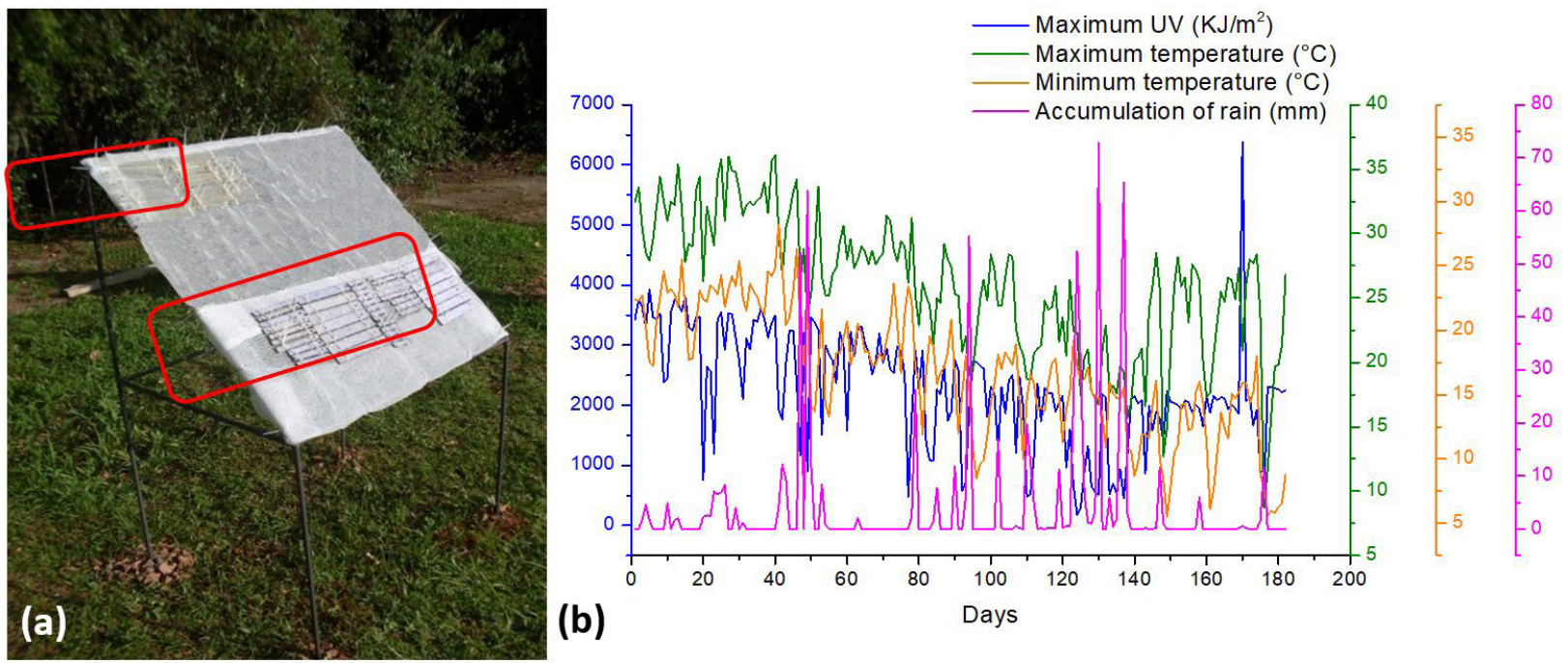

Figure 1. Metal structure for sample exposure (a) and observed climatic conditions (b).
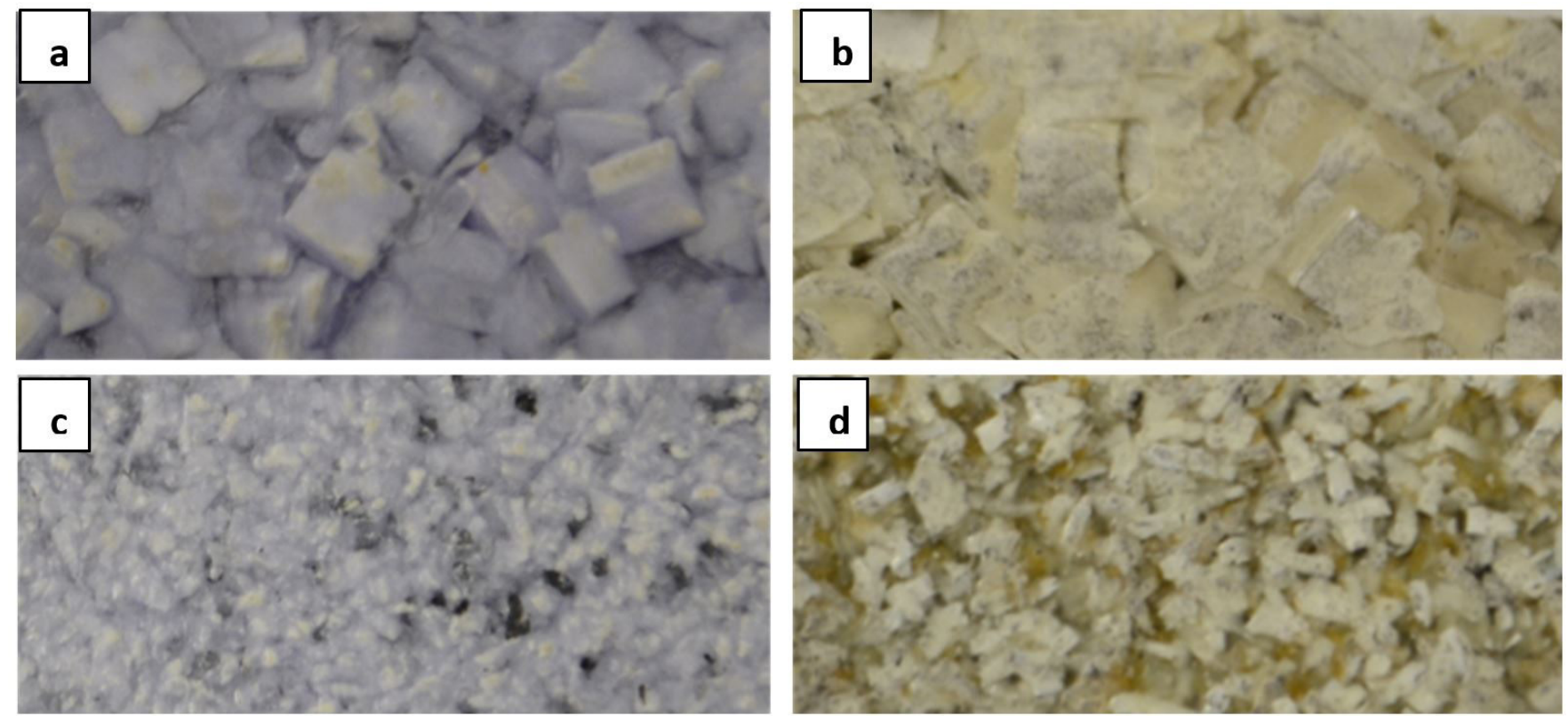

Figure 2. Change in the visual appearance of samples of PO/PMA $(a, b)$ and PO/PME (c, d) composites before and after aging respectively.

Through the study of natural aging (Figure 1), in which the samples are exposed to humidity, temperature, ultraviolet radiation and action of microorganisms, it is possible to evaluate the performance of the material under real conditions (AZWA et al., 2013). Visual inspection of the composites reveals that aging caused changes in visual appearance of the constituents (matrix and reinforcement) (Figure 2). Yellowing of the polyester resin occurs mainly caused by solar radiation (ANDRADY et al., 1998) and a combination of factors such as rainfall, UV radiation and temperature may cause leaching of the matrix, which lead to a greater exposure of waste paper on the surface of the composite, especially for PO/PME (Figure 2d).

No signs of cracks, warping and delamination were found on the surface of the composites after aging, but swelling (reaching $4.5 \mathrm{~mm}$ in thickness), texture variation, loss of gloss and surface yellowing were clear after exposure. For Twe \& Liao (2003) and Silva et al. (2017), these characteristics occur due to UV radiation, water absorption, degradation of the constituents and loss of interaction between them. Intensity of UV radiation in the material decreases as it moves away from the surface of UV 
penetration, being mostly a surface process. Similar to this study, Affzan et al. (2013) investigated the natural aging of kenaf fiber/polyester composites (70\% w/w of fiber) and reported color change and degradation in mechanical properties after 200 days.

\subsection{Mass gain of samples}

There was little mass variation in polyester with the aging $(0.6 \%)$. However, a more significant mass variation occurred for PO/PME and PO/PMA (1.2\% and $2.7 \%$, respectively) and this difference is justified by the hydrophilic nature of the paper (DAS, 2017) that facilitates water absorption. Bearing in mind that the composites have the same volume of waste paper, the greater mass gain for PO/PMA may be due to the comparatively lower surface area, making it more difficult for the resin to wet out the paper during molding, thus yielding larger dry paper regions and more voids, which in turn facilitate water absorption.

\subsection{Influence of natural aging on mechanical properties}

The mechanical properties of the polymeric composites reinforced by waste of vegetable origin were generally affected by natural aging. The influence of waste paper size was also observed. In the tensile strength results (Figure 3a), there were statistically significant changes after aging only for the PO/PMA sample, which may have occurred due to the lower composite quality and higher void content as a result of the poor wettability of that waste paper by the polyester resin.

In natural aging, hydrolytic, photo-oxidative and thermal degradation occur, which can result in rupture of polymer chains, directly affecting tensile strength of the material. And, in composites submitted to aging, the fiber/matrix interface is a critical region, where water can diffuse by capillarity. For lignocellulosic materials, which

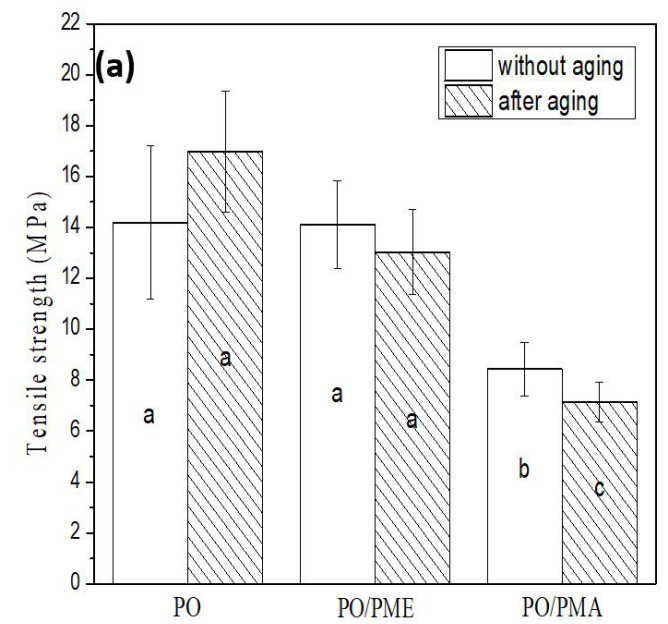

are hydrophilic, the oxidation reaction can be accelerated, reducing reinforcement/matrix adhesion by excess moisture (SILVA et al., 2017). Since the reinforcing material of this composite is paper, it easily absorbs water, creating hydrogen bonds and reducing interfacial interactions (AKIL et al., 2014).

In Figure 3b, a significant variation in tensile modulus was obtained by adding the paper in both PO/PME and $\mathrm{PO} / \mathrm{PMA}$ in relation to pure polyester (PO) prior to aging, as expected by the higher stiffness of the filler ( $>4 \mathrm{GPa}$ ) (PRAMBAUERA; PAULIK; BURGSTALLER, 2015) in relation to polyester. $\mathrm{PO}$ and the $\mathrm{PO} / \mathrm{PME}$ increased modulus after aging probably due to a higher degree of resin crosslinking during exposure (ALBUQUERQUE et al., 2000). Regarding PO/PMA, there was no increase in tensile modulus with aging perhaps because the gain in resin stiffness may have been counterbalanced by greater water absorption leading to a more sever plasticizing effect.

As for the flexural strength results (Table 1), the composites presented lower strength that the polyester, with or without aging, a limiting factor for the development of products that require this characteristic, especially if they are exposed to external areas. The decrease in flexural strength with aging was $9.5 \%, 14.8 \%$ and $39.6 \%$ for PO, $\mathrm{PO} / \mathrm{PME}$ and PO/PMA, respectively. This decrease is consistent with the observed moisture absorption, which was $\mathrm{PO}<\mathrm{PO} / \mathrm{PME}<\mathrm{PO} / \mathrm{PMA}$, which is expected to make the composite less stiff and strong.

The loss of adhesion and performance in bending was also verified by Akil et al. (2009) who studied jute/polyester composites subjected to different types of hygrothermal aging. And Affzan et al. (2013) observed a significant reduction in compression and flexural properties for unsaturated polyester reinforced with $70 \% \mathrm{w} / \mathrm{w}$ of kenaf fibers with aging, which was attributed to repeated solar

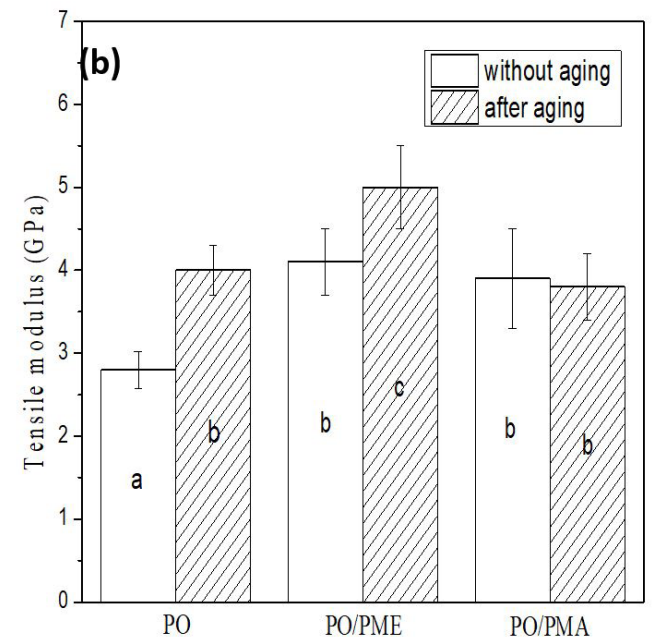

Figure 3. Tensile strength (a) and elasticity modulus (b) of composite materials before and after aging. Each different letter in the table represents a different result variability detected by Anova. 
Table 1. Flexural and impact strength, and hardness of the studied composites.

\begin{tabular}{|c|c|c|c|}
\hline Material & $\begin{array}{c}\text { Flexural strength } \\
(\mathrm{MPa})\end{array}$ & $\begin{array}{c}\text { Impact strength } \\
\left(\mathrm{kJ} / \mathrm{m}^{2}\right)\end{array}$ & $\begin{array}{c}\text { Hardness } \\
(\text { Shore D) }\end{array}$ \\
\hline PO & $75.07 \pm 3.31^{\mathrm{a}}$ & $0.69 \pm 0.06^{\mathrm{j}}$ & $76 \pm 1^{\mathrm{f}}$ \\
\hline Aged PO & $67.95 \pm 4.92^{\mathrm{a}}$ & $1.39 \pm 0.13^{\mathrm{l}}$ & $81 \pm 1^{\mathrm{g}}$ \\
\hline PO/PME & $38.60 \pm 2.44^{\mathrm{b}}$ & $1.67 \pm 0.17^{\mathrm{m}}$ & $83 \pm 1^{\mathrm{h}}$ \\
\hline Aged PO/PME & $32.89 \pm 3.58^{\mathrm{c}}$ & $3.98 \pm 0.61^{\mathrm{n}}$ & $83 \pm 1^{\mathrm{h}}$ \\
\hline PO/PMA & $21.59 \pm 1.58^{\mathrm{d}}$ & $2.25 \pm 0.22^{\mathrm{o}}$ & $85 \pm 1^{\mathrm{i}}$ \\
\hline Aged PO/PMA & $13.04 \pm 5.10^{\mathrm{e}}$ & $3.54 \pm 0.69^{\mathrm{n}}$ & $81 \pm 1^{\mathrm{g}}$ \\
\hline
\end{tabular}

Each different letter in the bar graph represents a different result variability detected by Anova.

heating, rain and dew moisture, with consequent fiber detachment and weakening of the fiber/matrix interface.

Results of the impact test are also shown in Table 1. There was an increase in strength of the composites in relation to pure polyester due to the insertion of a soft material in the brittle matrix (RAQUEZ et al., 2010). When the materials were exposed to moisture (aging), they became more ductile, which increased their toughness (ZIVKOVIC et al., 2017). As reported by Mejri et al. (2018), limited water absorption may increase mobility of the polymeric chain and result in increased impact strength.

As for the hardness results (Table 1), it can be seen that the pure resin becomes harder with the inclusion of the paper and also due to aging, the latter being justified by the already mentioned secondary crosslinking that occurs during that period. This effect is counterbalanced by water absorption, which tends to soften the material, and the composite with greater mass gain shows a significant decrease in hardness.

\section{Conclusions and recommendations}

In this study, the behavior of paper/polyester composites exposed to natural aging was evaluated. Before aging, the materials presented mechanical properties similar or superior to polyester, except for flexural strength. The particle size of the waste paper was found to influence the results after aging, and the polyester/large paper (PO/PMA) composite showed more degraded characteristics in general due to the poorer reinforcement/matrix adhesion, greater heterogeneity and larger voids, which increase water absorption.

Deleterious effects were found on tensile and flexural strength, and hardness of the composite, whereas impact strength increased also due to a plasticizing effect of the water. And secondary resin crosslinking during aging resulted in improved elasticity modulus. Based on these results combined with visual analysis, the developed materials were found unsuitable for products for external use, and the PO/PME composite is the best suited for application in the furniture industry, replacing MDF in the development of decoration parts, among others.

Considering the results of this study we would like to suggest the use of other industrial waste, such as sawdust and leather in thermoset matrixes, waste that can be submitted to surface treatments, differently from the waste paper used in this work that would decompose, in order to increase particle/matrix adhesion and thus reduce the water absorption of the material when exposed to natural aging and may even increase the mechanical properties in tensile and flexure after weathering compared to this work.

\section{Acknowledgements}

The authors would like to thank UFRGS' Print Shop by the project 8132-9 "Maintenance and Implementation of Sustainable Processes and Productions" for the financial support.

\section{References}

AFFZAN, M. H. et al. The effects of natural weathering on the properties of pultruded natural fiber reinforced unsaturated polyester composites. Materials Characterization VI, v. 77, p. 333-342, 2013.

AKIL, H. M. et al. Environmental effects on the mechanical behavior of pultruded jute / glass fiber-reinforced polyester hybrid composites. Composites Science and Technology, v. 94, p. 62-70, 2014.

AKIL, H. M. et al. Water absorption study on pultruded jute fiber reinforced unsaturated polyester composites. Composites Science and Technology, v. 69, p. 1942-1948, 2009.

ALBUQUERQUE, A. C. et al. Effect of wettability and aging conditions on the physical and mechanical properties of uniaxially oriented jute-roving-reinforced polyester composites. Composites Science and Technology, v. 60, p. 833-844, 2000.

AMERICA SOCIETY FOR TESTING AND MATERIALS ASTM. ASTM D256: standard test methods for determining the izod pendulum impact resistance of plastics. West Conshohocken: ASTM International, 2010.

AMERICA SOCIETY FOR TESTING AND MATERIALS - ASTM. ASTM D1435: standard practice for outdoor weathering of plastics. West Conshohocken: ASTM International, 2013. 
AMERICA SOCIETY FOR TESTING AND MATERIALS ASTM. ASTM D2240: standard test methods for standard test method for rubber property — durometer hardness. West Conshohocken: ASTM International, 2015.

AMERICA SOCIETY FOR TESTING AND MATERIALS - ASTM. ASTM D3039: standard test method for tensile properties of polymer matrix composite materials. West Conshohocken: ASTM International, 2017a.

AMERICA SOCIETY FOR TESTING AND MATERIALS - ASTM. ASTM D790: standard test methods for flexural properties of unreinforced and reinforced plastics and electrical insulating materials. West Conshohocken: ASTM International, 2017b.

ANDRADY, A. L. et al. Effects of increased solar ultraviolet radiation on materials. Journal of Photochemistry and Photobiology. B, Biology, v. 46, p. 96-103, 1998.

ANGRIZANI, C. C. et al. Analysis of curaua/glass hybrid interlayer laminates. Journal of Reinforced Plastics and Composites, v. 33, n. 5, p. 472-478, 2014.

ASHBY, M. F.; JOHNSON, K. Materials and design: the art and science of material selection in product. Oxford: Elsevier; 2014.

AZWA, Z. N. et al. A review on the degradability of polymeric composites based on natural fibres. Materials \& Design, v. 47, p. 424-442, 2013.

BELEC, L. et al. Comparative effects of humid tropical weathering and artificial aging on a model composite properties from nano- to macro-scale. Composites. Part A, Applied Science and Manufacturing, v. 68, p. 235241, 2015.

CHAN, C. M. et al. Mechanical and physical stability of polyhydroxyalkanoate (PHA)-based wood plastic composites (WPCs) under natural weathering. Polymer Testing, v. 73, p. 214-221, 2019.

DAS, S. Mechanical and water swelling properties of waste paper reinforced unsaturated polyester composites. Construction \& Building Materials, v. 138, p. 469-478, 2017.

FARUK, O. et al. Biocomposites reinforced with natural fibers. Progress in Polymer Science, v. 37, p. 1552-1596, 2012.
LIU, A. et al. A review of municipal solid waste environmental standards with a focus on incinerator residues. International Journal of Sustainable Built Environment, v. 4, p. 165$188,2015$.

MAZZANTI, V.; MOLLICA, F. Bending properties of wood flour filled polyethylene in wet environment. Procedia Engineering, v. 200, p. 68-72, 2017.

MEJRI, M. et al. Hygrothermal aging effects on mechanical and fatigue behaviors of a short natural-fiber-reinforced composite. International Journal of Fatigue, v. 108, p. 96-108, 2018.

PENCZEK, P.; CZUB, P.; PIELICHOWSKI, J. Unsaturated polyester resins: chemistry and technology. In: AMÉDURI, B. Crosslinking in materials science: technical applications. Berlin: Springer, 2005. p. 1-95. Advances in Polymer Science book series.

PORTAL RESÍDUOS SÓLIDOS. Reciclagem industrial de papel. 2018. Available from: <http://www.portalresiduos solidos.com/reciclagem-de-papel-2/\#more-2030>. Access in: 10 Mar 2018.

PRAMBAUERA, M.; PAULIK, C.; BURGSTALLER, C. The influence of paper type on the properties of structural paper - polypropylene composites. Composites. Part A, Applied Science and Manufacturing, v. 74, p. 107-113, 2015.

RAQUEZ, J.-M. et al. Thermosetting (bio)materials derived from renewable resources: a critical review. Progress in Polymer Science, v. 35, p. 487-509, 2010.

SCALICE, R. K.; BECKER, D.; SILVEIRA, R. C. Developing a new compatibility table for design for recycling. Product: Management \& Development, v. 7, n. 2, p. 141-148, 2009.

SILVA, C. B. et al. Effect of natural ageing on the properties of recycled polypropylene/ethylene vinyl acetate/wood flour composites. Revista Matéria, v. 22, n. 2, p. 1-12, 2017.

TWE, M. M.; LIAO, K. Durability of bamboo-glass fiber reinforced polymer matrix hybrid composites. Composites Science and Technology, v. 63, p. 375-387, 2003.

ZIVKOVIC, I. et al. Influence of moisture absorption on the impact properties of flax, basalt and hybrid flax/basalt fiber reinforced green composites. Composites. Part B, Engineering, v. 111, p. 148-164, 2017. 